\title{
Segmentation of Affected Crops using Deep Learning
}

\author{
S. Hemavathi, K. Jayasakthi Velmurugan
}

\begin{abstract}
Deep Learning technology can accurately predict the presence of diseases and pests in the agricultural farms. Upon this Machine learning algorithm, we can even predict accurately the chance of any disease and pest attacks in future For spraying the correct amount of fertilizer/pesticide to elimate host, the normal human monitoring system unable to predict accurately the total amount and ardent of pest and disease attack in farm. At the specified target area the artificial percepton tells the value accurately and give corrective measure and amount of fertilizers/ pesticides to be sprayed.
\end{abstract}

Index Terms - deep learning, perception, host

\section{INTRODUCTION}

Technology is playing a crucial in developing farms and agro-based industries. Today, it is possible to grow crops in deserts by using technology. Technology has dived into depths in agriculture sector. Automation technology is the present most demanded tool in agriculture. Many companies have come up with latest solutions in Machine Learning, Artificial Intelligence transforming agriculture into a Digital Agriculture. Many tests have proved that deploying technology in farms, will increase crop yield and farmer's revenue thereby.

Diagnosis is always a concern for farmers in India. At the same time due to fear of attack of pests/diseases, farmer uniformly sprays pesticides/fertilizers in whole farm which may lead to damage of soil as well as plant. The aim of this project is to make the farmer to spray a limited and enough pesticide/fertilizer at a specified target area where either pest/disease is present or maybe an occurrence of attack in future.

This helps the farmers mainly to prevent any such attacks on his farm as well as eliminate them if present any by spraying in limited amount and not polluting soil and other parts of plants. Major advantage of this is to increase farmer's annual monetary revenue and minimising crop loss caused by pests/infections attacks.

\section{LITERATURE REVIEW}

In India, there is a drastic change in Agri-Tech. Not most of the farmers are using latest tech gadgets in their farms. We often see IoT related agriculture in several journals but none of them are properly adopted in Indian farms.

Revised Version Manuscript Received on Jun 20, 2019.

S.Hemavathi, Faculty, Computer science and Engineering, Sri Sairam Engineering College, Chennai, India.

K.Jayasakthi velmurugan , Faculty, Computer Science and Engineering, Jeppiaar Engineering College, Chennai, India.
There is a huge gap between technology and farmers in India. Many start-ups have emerged to bridge this gap between the technology and the farmers. Now, even many MNCs are investing in Agri-Tech in India. Food demand is exponentially increasing due to rise in population. People talking about tractors and heavy machinery in farms era is now replaced by smart technology such as Internet of Things, Artificial Intelligence and Machine Learning. Smart sensors are replaced by heavy machinery in American farms. To produce food more sustainably, farmers are using technology such as temperature and needs measure the volumetric water content in soil,vibration to meet the landscape needs,topographic map and Global Positioning System track and receive alerts/rovers. On the report of "The Economist", farmers are being "teched up" which is used for growing crops/food more constant and profitable. It is often heard that pests and diseases attack crops and therefore food gradually reduces due to these attacks. By 2050, earth's population is expected to grow 9.7 billion. Therefore, a clear graph of rise in food demand is visible.

There are more changes introduced in new Agriculture methods.New techniques and methods are introduced in this field so farmers and others have considering weather and changes in climate conditions plays a vital role.New varieties of food types and food colouring increasein food production. This techniques leads to inprovements and enhancements to increase in food production, but crops lands are having a limited resource. The additional strains on agricultural production due to new request for bio energy or the change in the diet preference. We are expecting and observing changes in global climate, global warming ,Changing rainfall patterns, droughts, or the frequency increasing and time span of exceeding weather events leads to endanger.

Existing production areas identify the problems and solutions to the harvest yields globally. The difficulties what we are faced that can rectified by using other methods which are hard to identify, such as natural calametics, Economical or cost volatility in fresh products in the field of farming. Several digital apps are designed to help farmers to identify diseases attacked in the farm. Managing these challenges,we need a knowledge of reasonably using energy,enough water,manure etc.to increase the outcome of the production.[3].To protect the soil erosion and sustainability we need to use natural waste and tree leaves to aviod the soil waste and save the nature. Even NPK (Nitrogen, Phosphorus and Potassium) values of the plant are calculated to monitor the plant's health.

Many MNCs are investing hugely in using technology in agriculture. Artificial Intelligence, Machine learning,

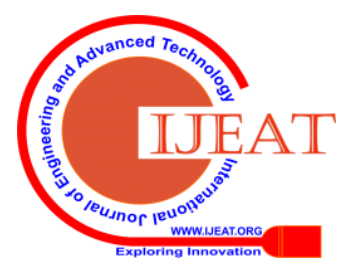




\section{Segmentation of Affected Crops using Deep Learning}

Deep learning and IoT technologies are adopted by startups and tech companies to boost the crop yield. Some apps are designed in such a way to predict the weather condition and soil condition and give an accurate measure to tell what kind and type of crop must be sown in the soil in order to withstand perfectly till the harvest time based on present and future conditions. So much of background research is going on to study the plant from A to $\mathrm{Z}$ mostly for prediction analysis in order to design algorithms using Machine Learning and Deep learning. Based on a single snap of a plant, A to $\mathrm{Z}$ analysis of it must be done, such type of research is going on to gather the necessary database.

All technical papers surveyed gave us a report of proving the interconnection among research component and Farming Field. Taking benefit from best in class detecting and actuator advances the commitments on Information Mining And Example Acknowledgment in farming tends to difficulties and possibilities of proper strategies in Horticulture. Roused by the requirement for expanded asset proficiency, the paper on robots for field activity with exhaustive multilayer control outline take a shot at the improvement of self-ruling rural machines. Streamlining the acti vities of a gathering coordinations chain, comprising of various collaborating vehicles in the field, will benefit from the utilization of dynamic course arranging calculations, as introduced in a paper on SPATIAL-Worldly CONSTAINT Arranging.

Finally, our survey concluded after interacting with several farmers that, most of the farmers are preferring apps because it's free and readily available $24 \times 7$ online. The farmer need not do much with it, he simply needs to take a snap of a plant and upload it to the cloud. The backend processing designed do the complete analysis of taken snap and gives a detailed report to the farmer. This involves even prediction analysis. All of this is possible only if required and accurate database is available to train the system. Hence, day by day research on algorithms are going on rather than focussing on hardware parts. Existing system discusses and tests Machine Learning technology implementation in agriculture. Diagnosis is always a concern for farmers in India. At the same time due to fear of attack of pests/diseases, farmer uniformly sprays pesticides/fertilizers in whole farm which may lead to damage of soil as well as plant. This system checks whether the crop is affected by pests/diseases by predicting the nutrient of the crop. The pest attack is identified by image processing technique. Due to spraying of pesticides/fertilizers the soil and the crops may get damaged. And the nutritient present in the soil may get spoiled. The Existing system can only find the affected region and cannot able to give the remedy suggestion. The system cannot able to give the accurate position of the affected crop in the agricultural farm.

\section{PROPOSED SYSTEM}

The aim of this project is to make the farmer to spray a limited and enough pesticide/fertilizer at a specified target area where either pest/disease is present or maybe an occurrence of attack in future. This helps the farmers mainly to prevent any such parts of plants.Major advantage of this is to increase farmer's annual monetary revenue and minimising crop loss caused by pests/disease attacks.

The image to be given as input is captured either in real time or its fed from API images in google and it is stored separately. The captured image is given as input image to our system. The resolution of this input image does not have any fixed pixel size so there is no need for image to be compressed. We can extract the wanted features from the particular images and delete the unwanted portions for further image processing. This method is used for improving the image quality and feature from attacks on his farm as well as eliminate them if present any by spraying in limited amount and not polluting soil and other

the low level to higher level. This module involves gray scale conversion and filtering by eliminating noise and refining picture element in the input image. In image segmentation module, the input image is partitioned into more number of segments. To locate objects and boundaries that is lines, curves, etc., in guise Image segmentation is used. Every pixel is assigned with a label so that same label share same characteristics. Clustering is used for segmenting the image into clusters having pixels with similar characteristics. Clustering involves dividing the training data into $\mathrm{X} \& \mathrm{Y}$ axes where a different feature gets classified into different classifications and corresponding labels.

\section{A. Proposed Architecture}

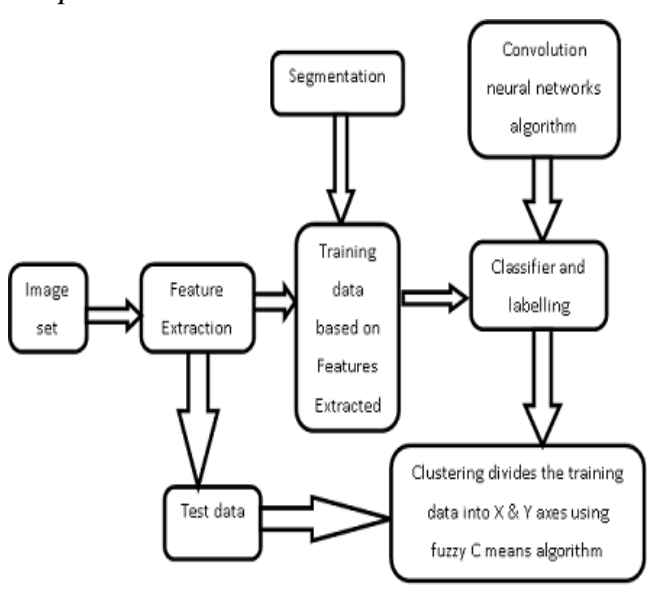

Fig.1.Architecture Diagram

\section{B.Segmentation}

In image segmentation module,the input image is partitioned into more no of segments. Objects and his boundaries can be located by using curves, lines and some other features in images. The smallest unit of an images is called pixels they can share some common characteristics.

\section{C.Classification}

Convolution neural networks algorithm is used for this classification purpose. The dataset of the plant leaf, various diseases, pests and soil images are trained in Matlab tool and classified into various clusters which classifies various labels. To identify the pest and diseases present in the form the iterative algorithm is used for finding final groups. This used in large data set and it will go for further implementation.

\section{Clustering}

It is the method used to segment the image into small Clusters. Clustering involves dividing the training data into $\mathrm{X} \& \mathrm{Y}$ axes where a different feature gets classified into different classifications and corresponding labels. 


\section{IV.RESULTS AND DISSCUSSION}

The specific diseases are identified from the particular plants that can be considered for test cases. Diseses can be identified in pest at the earlierstages so we can minimize the risks to save people and the society. Several pest control tools can be used to solve problems in pest. An applicationss introduced to detect the diseses in plant and provide a solutions to control the plant diseses. Newly introduced application can be implemented in different types of crops like Rice plant,Cotton and Sugarcane. To identify and improve detection of diseses in plants at various stages some samples from the affected crops are taken as input to the diseses identification methods so we can delivered the good crops without diseses in the crops in short period of time.Fully automated method will be introduced in the future to identify the diseses in the crops.
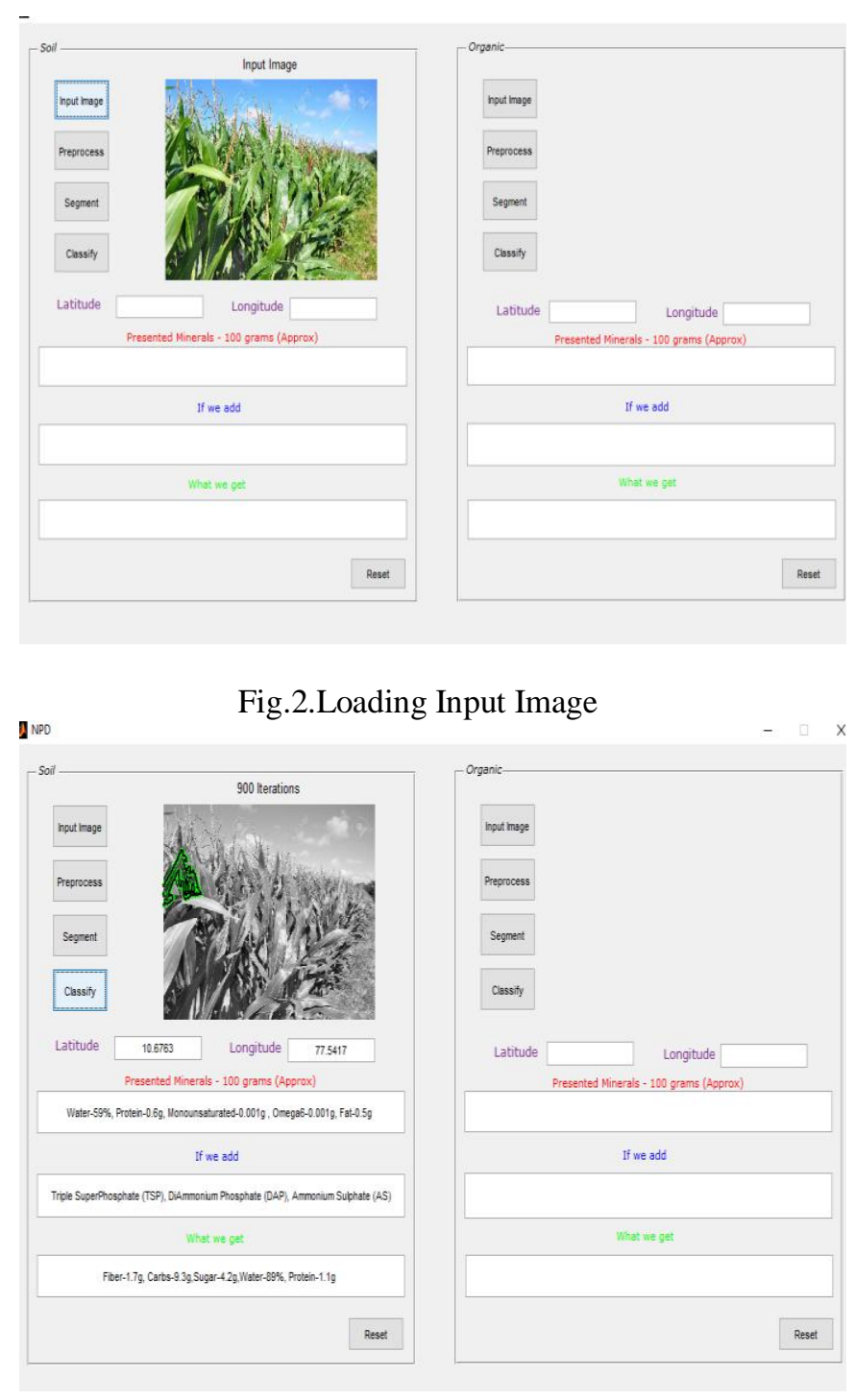

Fig.3.Classifying Input Image
Fig.4. Clustering of the Input Image and Displaying of Crop Disease

\section{REFERENCES}

1. E. H. Miller, "A note on reflector arrays (Periodical style-Accepted for publication)," IEEE Trans. Antennas Propagat., to be published.

2. M. Young, The Techincal Writers Handbook. Mill Valley, CA: University Science, 1989

3. Y. Yorozu, M. Hirano, K. Oka, and Y. Tagawa, "Electron spectroscopy studies on magneto-optical media and plastic substrate interfaces(Translation Journals style)," IEEE Transl. J. Magn.Jpn., vol. 2,

4. B. Smith, "An approach to graphs of linear forms (Unpublished work style)," unpublished.

5. M. Suresh Anand, N.Mohankumar,A.Kumaresan,"Developing Indian Sign Language Recognition System for Recognizing English Alphabets with Hybrid Classification Approach",Indian Journal of Public Health Research \& Development, Volume 9, Issue no. 2, Feb 2018

6. J. Wang, "Fundamentals of erbium-doped fiber amplifiers arrays" IEEE J. Quantum Electron., submitted for publication.

7. G. O. Young, "Synthetic structure of industrial plastics (Book style with paper title and editor)," in Plastics, 2nd ed. vol. 3, J. Peters, Ed. New York: McGraw-Hill, 1964, pp. 15-64.

8. C. J. Kaufman, Rocky Mountain Research Lab., Boulder, CO, private communication, May 1995

9. H. Poor, An Introduction to Signal Detection and EstimationW.-K Chen, Linear Networks and Systems (Book style). Belmont, CA Wadsworth, 1993, pp. 123-135.

\section{AUTHORS PROFILE}

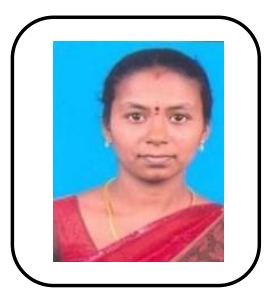

S.HEMAVATHI, is a Asst.Prof in the department of Computer Science and Engineering in Sri Sairam Engineering college west Tambaram. She Finished her B.Tech in 2004,SRM Easwari Engineering college,Madras University and Master degee in Madha engineering college in 2009, Anna University. She is having 15 years of Experience in Teaching and area of interest includes Networking,Inetnet of thimgs,Big data

K.Jayasakthi velmurugan is a Research Scholar in Computer Science and Engineering Discipline at Sathyabama University, Chennai. He obtained his M.E (CSE) in 2007, Anna University, Chennai and He Finished his B.E (CSE) in 2002 Bharathiar University. He is having 13 years of Experience in Teaching and His Research interest includes Image processing, Cloud Computing, Network Security and Mobile Computing.

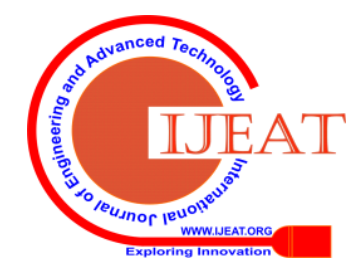

